\title{
ENRICHING SPATIAL DATA INFRASTRUCTURE (SDI) BY USER GENERATED CONTENTS FOR TRANSPORTATION
}

\author{
M. Shakeri, A. Alimohammadi, A. Sadeghi-Niaraki, A. A. Alesheikh
}

GIS Dept., Faculty of Geodesy and Geomatics Engineering, K.N.Toosi Univ. of Tech., Tehran, Iran. mshakeri@mail.kntu.ac.ir, alimoh-abb@kntu.ac.ir, a.sadeghi@kntu.ac.ir,alesheikh@kntu.ac.ir

KEY WORDS: User-centric SDI (spatial data infrastructure), Volunteered Geographic Information (VGI), transportation

\begin{abstract}
:
Spatial data is one of the most critical elements underpinning decision making for many disciplines. Accessing and sharing spatial data have always been a great struggle for researchers. Spatial data infrastructure (SDI) plays a key role in spatial data sharing by building a suitable platform for collaboration and cooperation among the different data producer organizations. In recent years, SDI vision has been moved toward a user-centric platform which has led to development of a new and enriched generation of SDI (third generation). This vision is to provide an environment where users can cooperate to handle spatial data in an effective and satisfactory way. User-centric SDI concentrates on users, their requirements and preferences while in the past, SDI initiatives were mainly concentrated on technological issues such as the data harmonization, standardized metadata models, standardized web services for data discovery, visualization and download. On the other hand, new technologies such as the GPS-equipped smart phones, navigation devices and Web 2.0 technologies have enabled citizens to actively participate in production and sharing of the spatial information. This has led to emergence of the new phenomenon called the Volunteered Geographic Information (VGI). VGI describes any type of content that has a geographic element which has been voluntarily collected. However, its distinctive element is the geographic information that can be collected and produced by citizens with different formal expertise and knowledge of the spatial or geographical concepts. Therefore, ordinary citizens can cooperate in providing massive sources of information that cannot be ignored. These can be considered as the valuable spatial information sources in SDI. These sources can be used for completing, improving and updating of the existing databases.

Spatial information and technologies are an important part of the transportation systems. Planning, design and operation of the transportation systems requires the exchange of large volumes of spatial data and often close cooperation among the various organizations. However, there is no technical and organizational process to get a suitable data infrastructure to address diverse needs of the transportation. Hence, development of a common standards and a simple data exchange mechanism is strongly needed in the field of transportation for decision support. Since one of the main purposes of transportation projects is to improve the quality of services provided to users, it is necessary to involve the users themselves in the decision making processes. This should be done through a public participation and involvement in all stages of the transportation projects. In other words, using public knowledge and information as another source of information is very important to make better and more efficient decisions. Public participation in transportation projects can also help organizations to enhance their public supports; because the lack of public support can lead to failure of technically valid projects. However, due to complexity of the transportation tasks, lack of appropriate environment and methods for facilitation of the public participation, collection and analysis of the public information and opinions, public participation in this field has not been well considered so far. This paper reviews the previous researches based on the enriched SDI development and its movement toward the VGI by focusing on the public participation in transportation projects. To this end, methods and models that have been used in previous researches are studied and classified initially. Then, methods of the previous researchers on VGI and transportation are conceptualized in SDI. Finally, the suggested method for transportation projects is presented. Results indicate success of the new generation of SDI in integration with public participation for transportation projects.
\end{abstract}

\section{INTRODUCTION}

Spatial data have become increasingly important with the development of technology. The public sector, private companies and all people attempt to collect, produce and use spatial data. Therefore, due to importance of the spatial data in various fields, particularly the transportation, spatial data sharing is an essential issue. Spatial Data Infrastructure (SDI) has the key role to facilitate spatial data sharing by providing an environment for essential collaboration and cooperation among the different organizations (Toomanian 2012). SDI initiatives support users in performing different tasks such as to acquire, process, analysis, share, distribute, use, maintain and preserve spatial data in a standard way. SDI concepts have been constantly evolving. The evolutions have been done due to social changes, increasing awareness about the importance of spatial data and technological advancements since their beginning in the 1990s (Henning et al. 2011). In recent years, SDI vision has been moved toward a user-centric platform which has led to development of a new and enriched generation of SDI called as the third generation. While in previous SDI models, users only receive data; in user-centric SDI, users can play a more active role and can simultaneously interpret and produce data (Budhathoki et al. 2008). Therefore, user-centric SDI is designed based on the user's requirements and preferences (Sadeghi-Niaraki et al. 2010).

The term Volunteered Geographic Information (VGI) first time was used by Goodchild to describe the diverse practices of observing, collecting and producing geographic information by ordinary citizens that have different expertise in spatial domain (Goodchild 2007). VGI have potential to develop SDIs for scientific and policy-support purposes (Álvarez et al. 2010). VGI provides a massive source of information that cannot be ignored. This information can be used to complete gaps in official data including cheap and up to date information (Núñez-Redó et al. 2011). 
Collaboration and coordination between the transportation organizations and relevant stakeholders such as the Department of Environment, Forests, Range and Watershed Management, Cultural Heritage and Tourism can facilitate the transportation projects. To this end, spatial data sharing is an important and also difficult issue. It is difficult, because transportation organizations use different data sets and software tools to support planning, design, construction, maintenance and operation of the transportation systems. But currently, there is no technical and organizational process to achieve an appropriate data infrastructure to handle diverse needs of the transportation. Therefore, development of common standards and simple data exchange mechanisms are strongly required to support effective decision making in transportation projects. Hence, spatial data infrastructure can be an ideal solution.

Transportation decisions are made with the goal of improving the quality of life of citizens. Therefore, public involvement is an integral part of the transportation projects which helps to ensure that decisions are made by consideration of benefits needs and preferences of the public. However, due to complexity of the transportation tasks, lack of appropriate environment and methods for collection and analysis of the public information and opinions and facilitation of the public participation, public participation in this field has not been well considered so far.

The goal of this paper is to investigate VGI and SDI integration approaches for introducing a data infrastructure that facilitate coordination between the different organizations and public participation in transportation projects. To accomplish this goal, after explaining the user-centric SDI concepts, some methods and models of VGI and SDI integration previous researches are classified. Then, previous researchers on public participation in transportation works are conceptualized in SDI. At the end, effective procedures for new road construction project in order to select the best route is proposed.

\section{Spatial data infrastructure}

Usage all available spatial data have been affected several challenges in spatial data collection, storage and distribution. To overcome different aspects of the current challenges in spatial data handling, Spatial Data Infrastructure (SDI) has been introduced. An SDI is a collaborative environment for managing, storing, and exchanging spatial data (Toomanian 2012). It is described as the underlying infrastructure, often in the form of policies, standards and access networks that allows data to be shared among people within organizations, states or countries. The fundamental interaction between people and data is governed by the technological components of SDI represented by the access network, policies and standards (Rajabifard et al 2003). Fig.1 shows dynamic inter-relationships between the people and spatial data within an SDI.

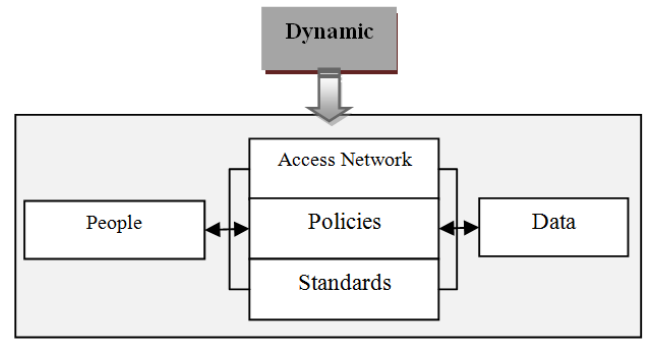

Figure1. Nature and relations between SDI components (Rajabifard et al 2003)

\subsection{User-Centric SDI}

With social changes, increasing awareness of importance of the spatial data and technological advancement, SDI concepts have been constantly evolving (Henning et al. 2011). The evolution of spatial data infrastructure can be divided in three generations, data-centric, process-centric, and user-centric (Sadeghi-Niaraki et al. 2010). Fig. 2 shows these three generations of SDI.

In the past, SDI initiatives concentrated mainly on technological issues such as data harmonization, standardized metadata models, standardized web services for data discovery, visualization and download (Henning et al. 2011). Preferences and requirements of users were not considered in these initiatives. Full potential of SDI in supporting spatial data sharing by users including the organizations and public, can be achieved only by the user-centric SDI that concentrates on users requirements (Henning et al. 2011).

The new paradigm of a third generation SDI is a platform which pays more attention to the needs of the users. In contrast, the first generation of SDI mainly concentrated on data collection and sharing, the second generation of SDIs focused on services and was based on specifications of the available data. In both cases, the final resulting infrastructure was not fully based on the user preferences (Lanz 2011).

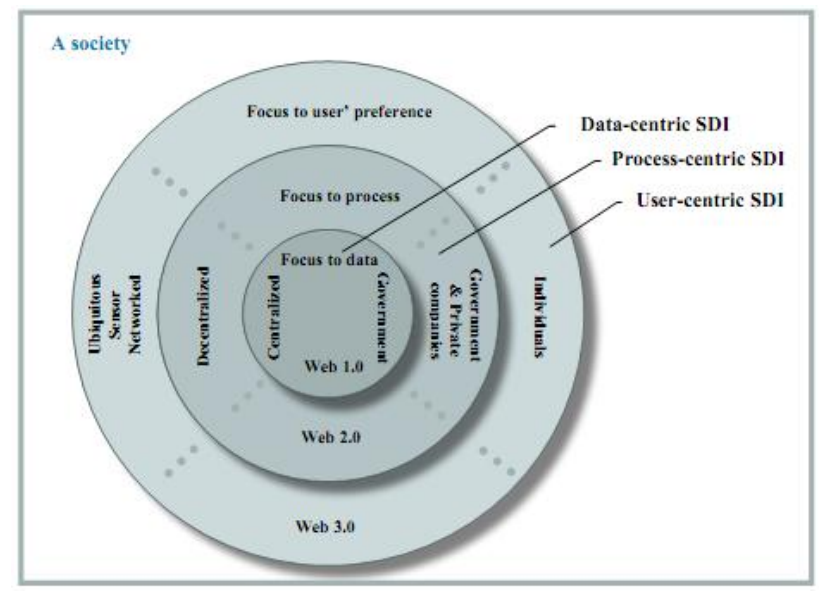

Figure 2. User-centric view acts as a key element of $3^{\text {rd }}$ generation of SDI (Sadeghi-Niaraki et al. 2010) 
While in the previous SDI models, users only received data; in user-centric SDI, users can play more active role and can simultaneously interpret and produce data (Budhathoki et al. 2008). Involvement of the user community in this process triggers a remarkable increase in user participation as compared to the previous concepts. In the first generation SDI's data was gathered by the governmental agencies and supported by various organizations. Second generation SDI started to involve users more closely in the development and implementation of the services. However, users don't play beyond the active recipient in the process-centric SDIs (Budhathoki et al 2008) and the user's interests for services/infrastructure designs are not fully considered. User-centric SDI is designed based on the users' requirements and preferences (Sadeghi-Niaraki et al. 2010) and spatial data needed are gathered by the active participation of public in addition to organizations. Therefore, public participation in producing and sharing of the spatial data is essential and key element in user-centric SDI.

\subsection{VGI in SDI}

Recent advancement in web 2.0 technologies and GPSequipped devices have provided participatory environment that have enabled ordinary citizen to produce and share spatial information. These advancements in information technology have converted the users to spatial data providers. These activities have created Volunteered Geographic Information (VGI) concept (Díaz et al. 2012). VGI have been used to describe the diverse practices of observing, collecting and producing geographic information by ordinary citizens that have different expertise in spatial domain (Goodchild 2007). In other words, VGI is voluntarily gathered by citizen. Distinctive element of VGI as compared to conventional information is that contributors are not trained in spatial concepts (Ho et al. 2010). VGI is a different approach from traditional ways of producing and sharing information.

VGI can be considered as alternative source in SDI to complement, improve and update the official information. Hence, results that are obtained from these SDI initiatives for geospatial analysis and decision support tasks are improved (Díaz et al. 2012a). Various researches have been done for integration of Web 2.0 resources within the SDI context.
Budhathoki et al. (2008) have Reconceptualized the role of SDI user from a passive recipient to an active information actor (which they called 'produser'), that allows users to produce and share geographic Information. Castelein et al. (2010) have used SDI components as a common framework to describe the main characteristics of VGI and to explore relations between the SDI and VGI. Coleman (2010) described risks and opportunities of VGI as a viable means of updating and enriching authoritative databases. Finally important questions are proposed that authoritative providers should answer when they consider VGI as a source of SDI. Mooney et al. (2011) explained some VGI problems (metadata, the nature of collaborative contributions, and data scale issues) that must be solved before becoming an active actor in SDI. Álvarez et al. (2010) empirically analyzed local SDI in the context of social networks: Facebook, MySpace, and Twitter.

Ho et al. (2010) proposed a conceptual framework including SDI geoportal. This geoportal has new elements such as wikis, mashups snd tags in its interface to support VGI characteristics. Sabone (2009) investigated the enabling technologies affecting the accuracy of VGI and specifying accuracy compliant with the Canadian Geospatial Data Infrastructure (CGDI) accuracy standards and designed a framework for integrating VGI into the suitable authoritative CGDI datasets that is based on methods for updating and validating data. Paudyal et al. (2012) presented a conceptual framework for how the spatial data infrastructure and catchment management activities are interlinked and how volunteered geographic information can contribute for catchment management activities.

Díaz et al. (2011) developed a distributed architecture based on the INSPIRE principles and extended with a Service Framework component to improve integration and development of data resources into SDI. This architecture assists users to wrap their own resources as the standard web services. Miranda et al. (2011) proposed a SDI architecture with new components of collaborative architecture for registration and administration of the volunteered geographic information on SDI data at the municipal level. Núñez-Redó et al. (2011), Díaz et al. (2012a) and Díaz et al. (2012b) developed traditional SDI architecture with a middleware component that provides homogeneous and standard search interface to retrieve and integrate data from social networks and crowdsourcing platforms into SDI databases. These works are classified into 4 groups as described in Table 1.

Table 1. Classification of past works on VGI and SDI integration

\begin{tabular}{|c|l|}
\hline Classification & \multicolumn{1}{c|}{ Description } \\
\hline $\begin{array}{c}\text { Concepts of relations between SDI } \\
\text { and VGI }\end{array}$ & $\begin{array}{l}\text { Describing concepts, challenges, opportunities and relations between } \\
\text { SDI and VGI (Castelein et al. 2010), (Coleman 2010), (Mooney et } \\
\text { al. 2011), (Álvarez et al. 2010), (Budhathoki et al. 2008). }\end{array}$ \\
\hline $\begin{array}{c}\text { Conceptual Framework } \\
\text { Data based integration }\end{array}$ & $\begin{array}{l}\text { Conceptual framework for considering VGI as a source of SDI are } \\
\text { proposed (Ho 2010), (Paudyal et al. 2012), (Sabone 2009). }\end{array}$ \\
\hline Users can deploy their own geographic information into SDI \\
databases (Díaz et al. 2011), (Miranda et al.)
\end{tabular}




\section{Public participation in Transportation}

The main purpose of transportation projects is to improve the quality of services provided to users. Therefore, it is essential that those affected by transportation decisions take part in the planning process in some way. Public involvement brings diverse viewpoints and values into the decision-making process. This process enables agencies to make better informed decisions through collaborative efforts and builds mutual understanding and trust between the agencies and the public they serve. Public participation in transportation projects can also help organizations to enhance their public supports; because lack of the public support can lead to failure of technically valid projects. In variety of transportation related activities, including the planning, formal policymaking, program and service design, and evaluation are important to get public participation in their process. Public participation in transportation projects takes a range of forms, from simply informing stakeholders about decisions, to considering their concerns in programs or policies under consideration, to involving them in producing and sharing data.

There is no a single formula for ensuring better public participation. Like transportation services or infrastructure, public participation needs to be designed for a particular context.

Various researches have been carried out in different fields of transportation, including the traffic planning (Wahl 2012), (Li 2013), safety programming (Kowtanapanich et al. 2006), intelligent transportation (Ali et al. 2012), (Lu 2009), routing (Shah et al. 2011), (Efentakis et al. 2012), (Stenneth et L. 2011) and environmental impact assessment (Alagan 2007). Table 2 demonstrates these research domains in public participation for transportation and describes their usage.

Table 2. Public participation in transportation domains

\begin{tabular}{|c|l|}
\hline Domain & \multicolumn{1}{|c|}{ Usage } \\
\hline Traffic Planning & $\begin{array}{l}\text { Collect real-time traffic } \\
\text { information using smart } \\
\text { phones }\end{array}$ \\
\hline Safety Programming & $\begin{array}{l}\text { Inform/ report the locations } \\
\text { with poor safety performance } \\
\text { (accident) }\end{array}$ \\
\hline $\begin{array}{c}\text { Intelligent } \\
\text { Transportation }\end{array}$ & $\begin{array}{l}\text { Collecting intelligent } \\
\text { transportation information }\end{array}$ \\
\hline Routing & $\begin{array}{l}\text { Reducing travel time by } \\
\text { reporting congestion, incidents, } \\
\text { crime incidents, events. }\end{array}$ \\
\hline $\begin{array}{c}\text { Environmental } \\
\text { Impact Assessment }\end{array}$ & $\begin{array}{l}\text { Representing social and } \\
\text { environmental issues of new } \\
\text { highways to people }\end{array}$ \\
\hline
\end{tabular}

Previous researches in different fields of transportation have shown to require coordination and data sharing between various stakeholders. These stakeholders can be transportation organizations, other related organizations to transportation project, private sectors and ordinary citizen with specific interests. For example, in addition to transportation organizations, police and forensics need the road events in safety programming. Information related Department of Environment, Forests, Range and Watershed Management Organization, Cultural Heritage and Tourism Organization are needed for environmental impact assessment. Therefore, SDI can facilitate coordination between various stakeholders including private and public organizations and general public.

\section{SDI-VGI based method for selecting the best route}

Transportation planning plays key role in the economic development of the regions. This fact has led to increasing demands to construct and extend highway systems. However, ecological and social impacts associated with transportation projects, have also generated a more critical attitude towards the large transport infrastructure projects by non-governmental organizations as well as the general public (Keshkamat et al. 2009). Identifying these impacts before implementing projects can help planners and decision makers to select a route that has the greatest positive impacts and the lowest negative impacts.

In transport route planning generally one or a few alternative routes are proposed. The process of selecting the best route for new road construction, is carried out with the environmental, social and economic evolution of alternatives, in addition to considering technical transportation criteria.. This process can fail without considering the cultural, social and economic patterns of the region, suitable programming for public participation in transportation planning and coordination between the different organizations (e.g. Department of Environment, Forests, Range and Watershed Management Organization, Cultural Heritage and Tourism Organization). In addition, lack of sufficient or updated information about the environment, social and cultural aspects of the region is one of the important problems. Therefore, spatial data infrastructure for developing common standards and data sharing mechanism between different organization, and public participation through producing and sharing spatial data and providing decision rules in order to complete data sources and to improve decision making can be considered for selecting best route. In other words, SDI and VGI integration can provide a good solution for selecting the best route for new road.

As shown in Fig. 3, the required data for selecting the best route are provided from SDI sources by coordination between different organizations and from VGI sources (after evaluating their quality). Initial analyses of these data are carried out for use in decision making process. Then, decision rules that are defined by experts as well as people are imposed on data according to the criteria affecting the best route selection, and thus, vulnerability maps are obtained for each alternative. Vulnerability maps are analyzed and finally best route alternative is selected that has lower environmental, social and economic impacts as well as high performance in technical transportation criteria. This method considers public concerns and also coordination between the different organizations. It shows many advantages such as the cost reduction in data production and increase of the public satisfaction. 


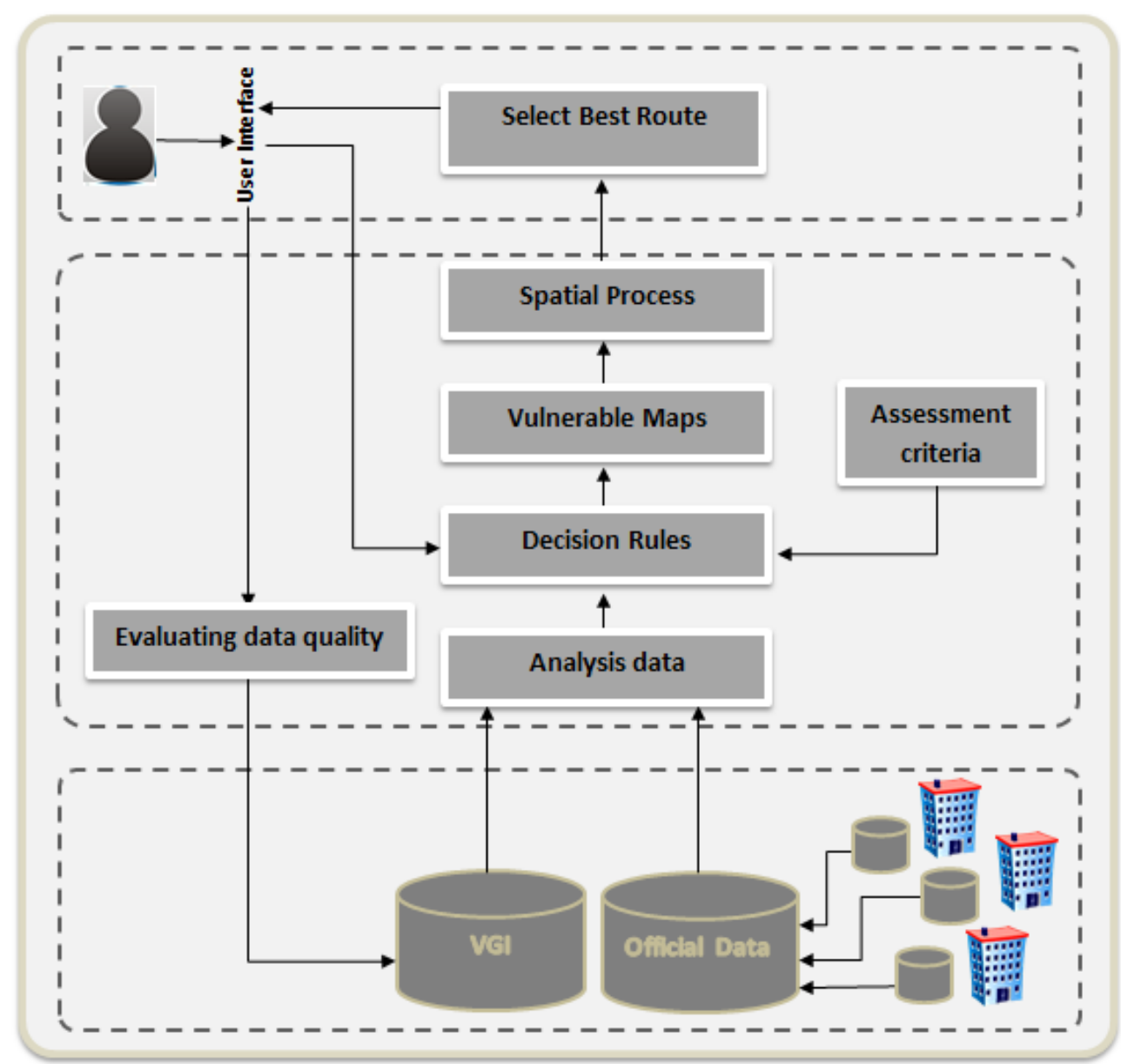

Figure 3. User involvement and coordination between different organizations for selecting the best route

\section{Conclusions}

Spatial data infrastructure concepts is continuously evolving. Recently, new and enriched generation of SDI has emerged. This generation is based on the user centric platform and considers ordinary citizens as producers of spatial data. Ordinary citizen can produce and share spatial information by recent technologies such as web 2.0. This information that can be named VGI is valuable source.

User-centric SDI has prominent role to increase public participation and to consider VGI as data source of SDI by considering needs and preferences of users into its design stage. VGI as source of SDI can be used to complete and update the available data.

For selecting the best route for new road construction project, SDI and VGI integration based method can have many advantages. Because it can provide a standard environment that facilitates coordination between different stakeholders including the private, public organization and general public. It also reduce costs in data production and increase of the public satisfaction. Therefore, selecting best route by this method have less conflicts of citizen, more compatible with environmental, social and economic issues.

\section{References}

Ali, K., Al-Yaseen, D. ,Ejaz, A. , Javed, T., Hassanein, H.S., 2012. CrowdITS: crowdsourcing in intelligent transportation systems, Wireless Communications and Networking Conference (WCNC), IEEE, pp. 3307-3311.

Alagan, R., 2007. Participatory GIS approaches to Environmental Impact Assessment: A case study of the Appalachian Corridor $\mathrm{H}$ Transportation Project, Dissertation submitted to the College of Arts and Sciences, Department of Geology and Geography, Morgantown, West Virginia.

Álvarez, M., Delgado Fernández, T., Cruz Iglesias, R., 2010. Social networks and Web 2.0 tools as a good complement to the local SDI's, Proceedings of the GSDI12, October 19- 22, Singapore.

Budhathoki, N. R., Bruce, B., and Nedovic-Budic, Z., 2008. Reconceptualizing the role of the user of spatial data infrastructure. GeoJournal (72), pp. 3 - 4.

Castelein, W., Grus, L., Crompvoets, J., and Bregt, A., 2010. A characterization of volunteered geographic information. XIII AGILE International Conference on Geo-graphic Information Science, Guimaraes, Portugal.

Coleman, D.J., 2010. Volunteered Geographic Information in Spatial Data Infrastructure: An Early Look At Opportunities And Constraints, 12th Global Spatial Data Infrastructure Association Conferences, October 19- 22, Singapore. 
Díaz, L., Granell, C., Gould, M. and Huerta, J., 2011. Managing user generated information in geospatial cyberinfrastructures, Future Generation Computer Systems, 27 (3), pp. 304-314.

Díaz, L., Nuñez, M., González, D., Gil, J., Aragó, P. and Pultar, E., 2012a. Interoperable search mechanism for Web 2.0 resources, International Journal of Spatial Data Infrastructure Research, vol. 7, pp. 277-299.

Díaz, 1., Granell, C., Huerta, J., Gould, M., 2012b. Web 2.0 Broker: A standards-based service for spatio-temporal search of crowd-sourced information, Elsevier, pp. 448-459.

Efentakis, A., Theodorakis, D., and Pfoser, D., 2012. Crowdsourcing computing resources for shortest-path computation. Proceedings of the 20th International Conference on Advances in Geographic Information Systems, pp. 434-437.

Goodchild, M.F., 2007. Citizens as Voluntary Sensors: Spatial Data Infrastructure in the World of Web 2.0. International Journal of Spatial Data Infrastructures Research, Vol. 2, pp. 24 - 32.

Henning, S. and BELGIU, M., 2011.User-centric SDI: Addressing Users Requirements in Third-Generation SDI. The Example of Nature-SDIplus, Geoforum Perspektiv - Tidsskrift for Geografisk Information. November 20.pp. 30-42.

Ho, S. and Rajabifard, A., 2010. Learning from the crowd: The role of volunteered geographic information in realising a spatially enabled society, Proceedings of GSDI 12 World Conference - Realising Spatially Enabled Societies, October 19-22, Singapore.

Keshkamat, S.S., Looijen, J.M. and Zuidgeest, M.H.P., 2009. The formulation and evaluation of transport route planning alternatives : a spatial decision support system for he Via Baltica project, Poland. In: Journal of transport geography, pp. 54-64.

Kowtanapanich, W., Tanaboriboon, Y., and Chadbunchachai, W., 2006. Applying public participation approach to black spot identification process, IATSS RESEARCH.

Lanz, M., 2011. Metadata Management Services for Spatial Data Infrastructure- A Case Study of a User-centric Implementation Strategy for an Academic Institution, Master Kartographie und Geoinformation, Universität Wien.

Li, R., 2013, A Study of Volunteered Geographic Information and Social Media, MSc thesis of Information Science Graduate Studies, University of Calgary.

Lu, X., 2009, Web Based Public Participation GIS Service for Intelligent Transportation Information Collection, 2nd International Conference on Power Electronics and Intelligent Transportation System (PEITS), vol. 1, pp. 274 - 277

Miranda, T. S., Lisboa-Filho, J., de Souza, W. D., da Silva, O. C. and Davis, C. A., Volunteered geographic information in the context of local Spatial Data Infrastructures.

Mooney, P. and Corcoran, P., 2011. Can volunteered geographic information be a participant in eEnvironment and sdi?, in Hreb'icek, J., Schimak G. and R. Denzer (eds), Environmental Software Systems. Frameworks of
eEnvironment, Vol. 359 of IFIP Advances in Information and Communication Technology, Springer Boston, pp. 115-122.

Núñez-Redó, M., Díaz, L., Gil, J., González, D. and Huerta, J., 2011. Discovery and integration of web 2.0 content into geospatial information infrastructures: A use case in wildfire monitoring, in Proc. of First International Conference on Massive Information Sharing and Integration, Vienna, Austria, pp. 50-68.

Paudyal, D. R., McDougall, Apan, K., A. , 2012. Exploring the application of volunteered geographic information to catchment management: A survey approach, ISPRS Annals of the Photogrammetry, Remote Sensing and Spatial Information Sciences, XXII ISPRS Congress, 25 August - 01 September, Melbourne, Australia,vol. I-4.

Rajabifard, A., Feeney, F., M.-E. and Williamson, I., 2003. Spatial Data Infrastructures: Concept, Nature and SDI Hierarchy, in Williamson, I. P., Rajabifard, A. \& Feeney, F., M.-E. (eds.) Developing Spatial Data Infrastructures: From Concept to Reality . Taylor and Francis, London, New York, pp. 17-40.

Sabone, B., 2009. Assessing Alternative Technologies for Use of Volunteered Geographic Information in Authoritative Databases, Unpublished M.Sc.E. Thesis, Department of Geodesy and Geomatics Engineering, University of New Brunswick, Fredericton, N.B. Canada.

Sadeghi-Niaraki, A., Rajabifard, A., Kim, K., and Seo, J., 2010. Ontology Based SDI to Facilitate Spatially Enabled Society, Proceedings of GSDI 12 World Conference, pp. 19-22.

Shah, S., Bao, F., Lu, C., Chen, I., 2011. CROWDSAFE: crowd sourcing of crime incidents and safe routing on mobile devices, In Proceedings of the 19th ACM SIGSPATIAL International Conference on Advances in Geographic Information Systems, pp. 521-524.

Toomanian, A., 2012. Methods to Improve and Evaluate Spatial Data Infrastructures, Centre for Geographical Information Systems (GIS Centre), Department of Physical Geography and Ecosystem Science, Lund University, Sweden.

Wahl, C., 2013. Swedish municipalities and public participation in the traffic planning process - Where do we stand?, Elsevier, vol. 50, pp. 105-112

Stenneth, L., Stone, W., Alowibdi, J., 2011. Reducing Travel Time by Incident Reporting via CrowdSourcing, in ICOMP'11. 